\title{
Minocycline improves learning and memory functions in ischemic stroke rats via reduction of cerebral ischemia- induced neuroinflammation and apoptosis
}

\author{
Li Li ${ }^{1}$, Xiaolian Xing ${ }^{2}$, Qian Li ${ }^{1}$, Qinqin Zhang ${ }^{1}$, Lu Fu ${ }^{1}$, Yi Liu ${ }^{1 *}$ \\ ${ }^{1}$ Department of Neurology, Shanxi Provincial People's Hospital, Taiyuan 030012, ²Department of Neurology, Taiyuan Central \\ Hospital, Taiyuan 030009, PR China
}

${ }^{*}$ For correspondence: Email: zpze79@163.com

Sent for review: 20 November 2020

Revised accepted: 27 January 2021

\begin{abstract}
Purpose: To study the effect minocycline on learning and memory functions in ischemic stroke rats, and the underlying mechanism.

Methods: 60 adult male SD rats were randomly divided into control group, ischemic brain damage (6 and 24 h MACO) groups; and 6 and $24 \mathrm{~h}$ minocycline groups, with 12 rats in each group. The volume of cerebral infarction, neuronal cell apoptosis, NF-KB protein expression, learning and memory ability, and the number of Iba-1+CD206-positive cells, and CD206/CD68 mRNA expressions in sham group, $6 \mathrm{~h}$ MACO group and $6 \mathrm{~h}$ minocycline group were determined and compared.

Results: The number of iba-1 +CD206-positive cells, expression level of CD206 mRNA, frequency of platform crossing, and percentage of third quadrant route in $6 \mathrm{~h}$ minocycline group were significantly higher than the corresponding values in $6 \mathrm{~h}$ MACO group. However, the cerebral infarction volume, number of Nini-positive cells, and the NF- B protein expression levels were markedly reduced, relative to corresponding values in $6 \mathrm{~h}$ MACO rats. The number of iba-1+CD206-positive cells was significantly lower in $6 \mathrm{~h} \mathrm{MACO}$ rats than in sham rats, while the expression level of CD68 mRNA was significantly higher $(p<0.05)$. The number of TUNEL-positive cells in 6 and $24 \mathrm{~h}$ minocycline groups were markedly lower than that in $6 \mathrm{~h}$ MACO group $(p<0.05)$.

Conclusion: Minocycline improves learning and memory of ischemic stroke rats by relieving the neuroinflammation induced by cerebral ischemia and cell apoptosis. Thus, the compound can be further developed for management learning and memory deficits in stroke patients.
\end{abstract}

Keywords: Minocycline, Apoptosis, Ischemic stroke, NF-kB

This is an Open Access article that uses a fund-ing model which does not charge readers or their institutions for access and distributed under the terms of the Creative Commons Attribution License (http://creativecommons.org/licenses/by/4.0) and the Budapest Open Access Initiative (http://www.budapestopenaccessinitiative.org/read), which permit unrestricted use, distribution, and reproduction in any medium, provided the original work is properly credited.

Tropical Journal of Pharmaceutical Research is indexed by Science Citation Index (SciSearch), Scopus, International Pharmaceutical Abstract, Chemical Abstracts, Embase, Index Copernicus, EBSCO, African Index Medicus, JournalSeek, Journal Citation Reports/Science Edition, Directory of Open Access Journals (DOAJ), African Journal Online, Bioline International, Open-J-Gate and Pharmacy Abstracts

\section{INTRODUCTION}

Cerebrovascular disease is one of the three major fatal diseases of human beings, and the treatment time window is extremely short. Survivors often have aphasia, epilepsy, paralysis and other post-treatment manifestations which bring a heavy burden to their health [1]. Ischemic stroke is one of the common pathological types of cerebrovascular diseases. Under pathological conditions, impairment of cerebral blood supply leads to ischemia and hypoxia, necrosis and 
softening of local brain tissues, and ultimately focal or complete defects in neurological function [2]. Clinical literature has shown that inflammatory response occurs within a few hours after activation of cerebral ischemia and microglia cells. The role of microglia in this process is extremely complex, and involves a restorative effect through secretion of related neurotrophic factors. In addition, they directly activate phagocytosis of necrotic tissues $[3,4]$.

At present, there is lack of effective treatment method for patients with ischemic stroke, a health-threatening disease. Therefore, elucidation of the pathological mechanism of ischemic stroke is of great significance for evolving new treatment methods and intervention targets for the disease. Minocycline is an antiinflammatory and bactericidal agent which has been widely used in clinical practice [5]. Clinical studies have shown that minocycline significantly inhibits the proliferation of microglia cells and secretion of inflammatory mediators after neonatal cerebral hemorrhage, thereby playing a protective role in the brain [6]. Other reports have shown that minocycline effectively reduces neuronal apoptosis induced by middle cerebral artery occlusion and ischemic brain injury in rats, but its therapeutic target and related molecular mechanism have not been elucidated [7]. Therefore, the purpose of this study was to investigate the effect of minocycline on learning and memory function in ischemic stroke rats, and the mechanism involved.

\section{EXPERIMENTAL}

\section{Materials}

Sixty (60) adult male SD rats were purchased from Nanjing Junke Bioengineering Co. Ltd [production license: SCXK (su) 2019-0018]. All rats were kept in cages (four per cage) in an environment with average temperature of $24 \pm 2$ ${ }^{\circ} \mathrm{C}$ and relative humidity of $55 \pm 5 \%$, with ad libitum access to diet and water. The study was commenced after 7 days of adaptive feeding. This research was approved by the Animal Ethical Committee of Taiyuan Central Hospital (approval no. 201903042) and was carried out according to the guidelines of "Principles of Laboratory Animal Care" (NIH publication no. 8523, revised 1985) [8].

\section{Main reagents and instruments}

Minocycline was purchased from Shanghai Qichun Industrial Co. Ltd. TUNEL Kit was purchased from Wuhan Purity Biotechnology Co. Ltd. Tissue embedding agent was bought from
Kilton Biotechnology (Shanghai) Co. Ltd, while fluorescent quantitative PCR reagent was purchased from Guangzhou Yingzang Biotechnology Co. Ltd. Protein lysate was obtained from Shenzhen Zike Biotechnology Co. Ltd. Immunofluorescence first antibody diluent was product of Guangzhou Peiyu Biological Products Co. Ltd. Immunofluorescence secondary antibody diluent was produced by Beijing Baiolaibo Technology Co. Ltd, while NF$\mathrm{KB}$ monoclonal antibody was purchased from Chuzhou Shnuoda Biotechnology Co. Ltd.

Cell incubator was purchased from Beijing Taize Jiaye Technology Development Co. Ltd. Super clean workbench was obtained from Hangzhou Nuoding Scientific Equipment Co. Ltd. Slicer was bought from Guangzhou Kesite Scientific Instrument Co. Ltd. Fetal bovine serum was purchased from Han Hengsheng Material Engineering (Shanghai) Co. Surgical microscope was product of Leica Microsystems (Shanghai) Trading Co. Ltd. Confocal laser microscope was purchased from Beijing Delica Biotechnology Co. Ltd, while electronic balance was bought from Sedris Group, Germany.

\section{Animal grouping and studies}

Thirty-six (36) healthy adult SD rats were divided randomly into sham group, middle cerebral injury occlusion group, $6 \mathrm{~h}$ MACO occlusion group, ischemic brain injury (6 h MACO) group, control group (24 h MACO), $6 \mathrm{~h}$ minocycline group, and $24 \mathrm{~h}$ minocycline group, each with 12 rats. The sham animals had threading and non-ligation. The $6 \mathrm{~h}$ MACO, $24 \mathrm{~h}$ MACO, $6 \mathrm{~h}$ minocycline and $24 \mathrm{~h}$ minocycline groups of rats were established using the method of line switch on rat cerebral ischemic damage.

Six rats were taken from each group at $72 \mathrm{~h}$ post-surgery. The rats were sacrificed immediately under chloral hydrate anesthesia. Their brain tissues were excised, and sections were prepared. Cerebral infarction areas of the rats in each group with ischemic stroke were determined using TTC staining. Apoptosis in each group was determined using TUNEL staining and Nidner staining to detect apoptosis of nerve cells in rats with ischemic stroke. Immunofluorescence staining was used to determine morphological changes in microglia cells in each group [M2-type microglia-specific protein (iba-1 +CD206)].

Real-time fluorescence quantitative PCR and immunoblotting were used to assay the mRNA and protein expressions of microglia-specific (M1 microglial CD206) and nuclear transcription 
factor-kB (NF-kB) in brain tissues of sham group and $6 \mathrm{~h}$ minocycline. On $28^{\text {th }}$ day after surgery, the remaining rats in each group were subjected to Morris water maze experiment for learning and memory ability, and the number of times the rats crossed the platform and the percentage of the distance to the third quadrant were recorded and analyzed.

\section{Statistical analysis}

Measurement data are expressed as mean \pm standard deviation (SD). Two-group comparison was done using independent sample $t$-test, while multi-group comparison was done with single factor ANOVA. All statistical analyses were carried out using GraphPad Prism 6.01 software. Values of $p<0.05$ were regarded as indicating significant differences.

\section{RESULTS}

\section{Cerebral infarction volume}

As shown in Table 1, the cerebral infarction volumes of the $6 \mathrm{~h}$ MACO group and the $24 \mathrm{~h}$ MACO group were significantly higher than that of the sham group, while the cerebral infarction volume of the $6 \mathrm{~h}$ minocycline ischemic stroke rats was significantly lower than that of $6 \mathrm{~h}$ MACO group $(p<0.05)$.

Table 1: Cerebral infarction volumes of the ischemic stroke rats

\begin{tabular}{lc}
\hline Group & $\begin{array}{c}\text { Volume of cerebral } \\
\text { infarction }\left(\mathbf{c m}^{\mathbf{3}}\right)\end{array}$ \\
\hline Sham & 0.00 \\
$6 \mathrm{~h}$ MACO & $40.15 \pm 3.45 \mathrm{a}$ \\
24h MACO & $41.15 \pm 3.26^{\mathrm{a}}$ \\
6h minocycline & $33.03 \pm 2.99^{\mathrm{b}}$ \\
24h minocycline & $39.25 \pm 3.10$ \\
\hline Data are presented as mean $\pm \mathrm{SD} .{ }^{\mathrm{a}} P<0.05$, vs \\
sham; ${ }^{\mathrm{b}} p<0.05$, vs $6 \mathrm{~h}$ MACO group \\
\multicolumn{2}{l}{ M2-type microglia-specific protein and M1/M2 } \\
microglia-specific mRNA expression levels
\end{tabular}

The number of iba-1 +CD206-positive cells in 6h MACO rats was significantly lower than that in sham rats, and the mRNA expression level of CD68 was markedly higher than that of the sham group. The number of iba-1 +CD206-positive cells and the expression level of CD206 mRNA in $6 \mathrm{~h}$ minocycline group were significantly higher than the corresponding values in $6 \mathrm{~h}$ MACO group $(p<0.05)$. These results are presented in Table 2.
Table 2: Iba-1 +CD206 positive cell number, CD68 and CD206 mRNA expression levels in ischemic stroke rats

\begin{tabular}{lccc}
\hline Group & $\begin{array}{c}\text { Iba-1+CD206 positive } \\
\text { cell number }\end{array}$ & CD68 & CD206 \\
\hline Sham & $6.35 \pm 1.36$ & $0.15 \pm 0$ & $0.24 \pm 0$ \\
6h & $5.23 \pm 1.02^{\mathrm{a}}$ & $0.28 \pm 0$ & $0.19 \pm 0$ \\
MACO & & $.08^{\mathrm{a}}$ & .07 \\
6h & $9.61 \pm 1.11 \mathrm{~b}$ & $0.09 \pm 0$ & $0.33 \pm 0$ \\
minocycli & & .05 & $.08 \mathrm{~b}$ \\
ne & & ${ }^{a} P<$ & $0.05, \mathrm{vs}$
\end{tabular}

sham group; ${ }^{b} P<0.05$, vs 6 h MACO group

\section{Neuronal cell apoptosis in rats with ischemic stroke}

The populations of TUNEL-+ve cells and Nissl+ve cells in the $6 \mathrm{~h}$ MACO group and the 24 MACO group were markedly higher than the sham values, while the populations of TUNEL+ve cells in $6 \mathrm{~h}$ minocycline group and $24 \mathrm{~h}$ minocycline group were significantly lower than the corresponding value in $6 \mathrm{~h}$ MACO group. Nicotine-positive cell population was significantly lower in $6 \mathrm{~h}$ minocycline group than in $6 \mathrm{~h}$ MACO group $(p<0.05)$. These results are presented in Table 3.

Table 3: Neuronal apoptosis in rats with ischemic stroke

\begin{tabular}{|c|c|c|}
\hline Group & $\begin{array}{l}\text { TUNEL-positive } \\
\text { cell number }(\mathrm{n})\end{array}$ & $\begin{array}{l}\text { Nissl-positive } \\
\text { cells (n) }\end{array}$ \\
\hline Sham group & $28.01 \pm 7.54$ & $49.35 \pm 3.02$ \\
\hline 6h MACO & $72.19 \pm 4.96^{a}$ & $75.11 \pm 6.01^{a}$ \\
\hline $\begin{array}{l}\text { 24h MACO } \\
6 \mathrm{~h}\end{array}$ & $86.10 \pm 5.03^{a}$ & $80.23 \pm 5.99^{a}$ \\
\hline $\begin{array}{l}\text { minocycline } \\
24 \mathrm{~h}\end{array}$ & $33.07 \pm 5.78^{b}$ & $55.01 \pm 4.09^{b}$ \\
\hline minocycline & $61.03 \pm 4.58^{\mathrm{b}}$ & 71.035 .79 \\
\hline
\end{tabular}

\section{NF-KB protein expression levels in apoptotic} pathways of rats with ischemic stroke

As shown in Table 4 and Figure 3, levels of NF$\mathrm{KB}$ protein in $6 \mathrm{~h}$ MACO group and $24 \mathrm{~h}$ MACO group were significantly higher than those in sham group, while level of NF-kB protein in $6 \mathrm{~h}$ minocycline group was significantly lower than that in 6 h MACO group $(p<0.05)$.

\section{Learning and memory capacities of ischemic stroke rats}

Table 5 shows that the number of platform crossings and the percentage of the third quadrant route were significantly lower in the $6 \mathrm{~h}$ 
MACO group and the $24 \mathrm{~h}$ MACO group than in sham group. The frequency of platform crossings in the $6 \mathrm{~h}$ minocycline ischemic stroke rats and the percentage of third quadrant route were markedly higher than those of $6 \mathrm{~h}$ MACO group $(p<0.05)$.

Table 4: NF-kB protein expression levels in ischemic stroke rats

\begin{tabular}{lc}
\hline Group & NF-KB \\
\hline Sham & $0.43 \pm 0.35$ \\
6h MACO & $0.75 \pm 0.23^{a}$ \\
24h MACO & $0.76 \pm 0.25^{\mathrm{a}}$ \\
6h minocycline & $0.49 \pm 0.28^{\mathrm{b}}$ \\
24h minocycline & $0.70 \pm 0.25$ \\
\hline Data are expressed as mean \pm SD. ${ }^{a} P<0.05$, vs \\
sham group; ${ }^{b} p<0.05$, vs MACO 6 h group
\end{tabular}

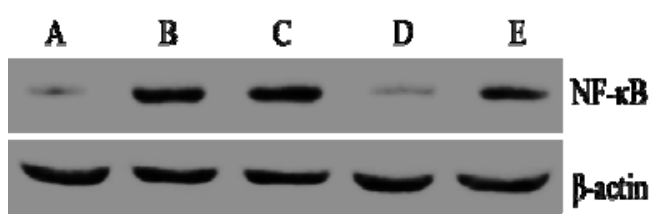

Figure 1: NF-kB protein expression levels in ischemic stroke rats. A: Sham operation group; B: $6 \mathrm{~h}$ MACO group; C: $24 \mathrm{~h}$ MACO group; D: $6 \mathrm{~h}$ minocycline group; E: 24 h minocycline group

Table 5: Number of platform crossings and percentage of third quadrant route amongst the groups with ischemic stroke

\begin{tabular}{|c|c|c|}
\hline Group & $\begin{array}{c}\text { Number of } \\
\text { station-crossings } \\
\text { (n) }\end{array}$ & $\begin{array}{c}\text { Third } \\
\text { quadrant } \\
\text { route (\%) } \\
\end{array}$ \\
\hline Sham & $6.64 \pm 0.52$ & $54.03 \pm 3.78$ \\
\hline 6h MACO & $4.96 \pm 0.43^{a}$ & $43.19 \pm 1.59^{a}$ \\
\hline 24h MACO & $4.43 \pm 0.46^{a}$ & $46.79 \pm 1.42^{a}$ \\
\hline $\begin{array}{l}6 \mathrm{~h} \\
\text { minocycline }\end{array}$ & $6.13 \pm 0.56^{b}$ & $52.83 \pm 3.08^{b}$ \\
\hline $\begin{array}{l}24 \mathrm{~h} \\
\text { minocycline }\end{array}$ & $5.49 \pm 0.49$ & $47.12 \pm 0.98$ \\
\hline
\end{tabular}

\section{DISCUSSION}

Ischemic stroke accounts for about $2 / 3$ of cerebrovascular diseases, and it is one of the major causes of high morbidity and mortality in humans. Currently, clinical findings show that many treatment methods have positive impact on the condition of patients. However, only thrombolytic therapy has been proven to be reliable, although only a few patients benefit from it [9]. Although animal-based studies have shown that many types of drugs effectively act as neuroprotective agents, they are not effective in clinical practice mainly due to numerous adverse drug reactions or very narrow therapeutic windows [10].
The processes involved in the pathogenesis of ischemic stroke are extremely complex, especially the link between ischemic hypoxia induced by cerebral ischemia and inflammatory response, which involves interactions of many types of nerve cells and immune cells. With the deepening of studies, reports on ischemic stroke have become the focus of neuro-professional research. However, the pathogenesis and intervention targets of the disease have not been fully elucidated, and no effective treatments are available. Therefore, the present study was aimed at evolving a neuroprotective drug that can effectively treat ischemic cerebrovascular diseases without toxicity and side effects.

Minocycline is a tetracycline derivative and an anti-inflammatory drug regularly used in clinics. Clinical reports have shown that minocycline has a high blood-brain barrier penetration capacity. It activates anti-inflammatory mechanisms, thereby regulating many types of neurofunctional diseases, including Alzheimer's disease [11]. Minocycline is currently recognized as an inhibitor of microglia cells, and it achieves neuroprotection by blocking the expression of matrix metalloproteinases [12]. Reports related to the nervous system have shown that minocycline exerts antioxidant, anti-apoptotic and antiinflammatory effects in stroke and other diseases [13]. In this study, it was found that minocycline mitigated early cerebral infarction in rats to a certain extent. However, with increase in duration of ischemic time, the ischemic volume of brain tissue tended to increase further, and the drug did not improve the long-term learning and memory ability of rats.

It has been reported that after the destruction of early brain tissue, microglia are activated in a variety of forms, among which is M1-type microglia which exert neurotoxic effect, and M2type microglia which exert neuroprotective effect. Clinical reports have shown that M1-type microglia participate and play an important role in neuroinflammatory response after activation by interleukin-6 release.

Tumor necrosis factor accelerates apoptosis of peripheral nerve cells due to other inflammatory mediators, and further aggravates brain injury [14]. The M2-type microglia release cerebral protective factors such as brain-derived neurotrophic factors which enhance nerve cell repair. Clinical literature shows that $M 1$ and $M$ microglia express different specific protein molecules. Therefore, studies have found that minocycline reduces MACO microglia-mediated M1 type, and also increases the expression level of M2 microglia-specific protein CD206, thereby 
exerting nerve protective effect. The NF-kB pathway is involved in the regulation of neuroinflammatory responses, and it plays a key role in ischemic stroke. The phosphorylation of NF-KB accelerates transcriptional transposition of NF-KB heterodimer P65/P50 in the neuronal cell membrane, leading to apoptosis [15]. In this study, it was found that minocycline significantly blocked NF-kB protein expression and reduced the number of neuronal apoptosis.

\section{CONCLUSION}

Minocycline improves learning and memory in ischemic stroke rats by relieving neuroinflammation-induced by cerebral ischemia and cell apoptosis. Therefore, minocycline may improve learning and memory function in patients with ischemic stroke.

\section{DECLARATIONS}

\section{Acknowledgement}

This research was supported by Shanxi Province key research and development program (Guide) project, pathogenesis research and treatment of cardiovascular and cerebrovascular diseases Observation on the influence of acute cerebral infarction over perfusion on prognosis and changes of serum S100 protein and hs-CRP (no. 201603D321059)

\section{Conflict of interest}

No conflict of interest is associated with this work.

\section{Contribution of authors}

Yi Liu was involved in the conceptualization and design of the study, manuscript revision, funding support and study supervision. Li Li contributed to design of the study as well as the experiments, data analysis and manuscript writing. $\mathrm{Li} \mathrm{Li}$, Xiaolian Xing, Qian Li, Qinqin Zhang, Lu Fu, Yi Liu contributed to the design of the study and interpretation of the data. All authors read and approved the final manuscript.

\section{Open Access}

This is an Open Access article that uses a funding model which does not charge readers or their institutions for access and distributed under the terms of the Creative Commons Attribution License (http://creativecommons.org/licenses/by/ 4.0) and the Budapest Open Access Initiative (http://www.budapestopenaccessinitiative.org/rea d), which permit unrestricted use, distribution, and reproduction in any medium, provided the original work is properly credited.

\section{REFERENCES}

1. Marei HE, Hasan A, Rizzi R, Althani A, Afifi N, Cenciarelli $C$, Caceci Thomas, Shuaib Ashfaq. Potential of Stem Cell-Based Therapy for Ischemic Stroke. Front Neurol 2018; 9: 34-38.

2. Craig SA, Thompson R, Richard IL, Hisatomi A, John C. Low-Dose versus Standard-Dose Intravenous Alteplase in Acute Ischemic Stroke. N Engl J Med 2018; 374(24): 2313-2323.

3. Liu D, Zhao Z, Wang A, Ge S, Wang H, Zhang X, Qi S, Weijie C Ming S, Lijuan $W$, et al. Ischemic stroke is associated with the pro-inflammatory potential of $\mathrm{N}$ glycosylated immunoglobulin G. J Neuroinflamm 2018; 15(1):123-126.

4. Nampet J, Malinee L, Siwanon R, Porjai P. Prognostic models for complete recovery in ischemic stroke: a systematic review and meta-analysis. BMC Neurol 2018; 18(1): 26-28.

5. Yen-Chung L, Yung-Chun C, Chih-Peng C, Yee-Shin L, Guey-Chuen P, Han-Chung W, Shie-Liang H, Trai-Ming $Y$. Minocycline suppresses dengue virus replication by down-regulation of macrophage migration inhibitory factor-induced autophagy. Antiviral Res 2018; 155: 2838.

6. Jonathan BS, TKent T, Masaya M, Matt M, Brent E, Matt $M$, Douglas $D$, William $Y$, Ondria $G$, Wayne $C D$. Treatment of bipolar depression with minocycline and/or aspirin: an adaptive, $2 \times 2$ double-blind, randomized, placebo-controlled, phase IIA clinical trial. Transl Psychiatry 2018; 8(1): 27-29.

7. Belén R, Aranzazu S, Rosario C, Luis F, Ágata L, Gema IE, Maria EMS, Marta RO, Julián LH, Teresa RP, et al. $A$ randomized placebo controlled clinical trial to evaluate the efficacy and safety of minocycline in patients with Angelman syndrome (A-MANECE study). Orphanet $J$ Rare Dis 2018; 13(1): 144-146.

8. World Health Organization. Principles of laboratory animal care. WHO Chron 1985; 39: 51-56.

9. Anna MMB, Ivo GHJ, Ludo FMB, Thomas GD, Luis SR, Ji $H H$, Marc $R$, Scott B, Mohammed AA, David SL. Association of follow-up infarct volume with functional outcome in acute ischemic stroke: a pooled analysis of seven randomized trials. Stroke 2018; 48(7): 1862-1865.

10. Gąsecki Dariusz, Coca A, Cunha P, Hering D, Manios E, Lovic $D$, Zaninelli A, Sierra $C$, Kwarciany $M$, Narkiewicz $K$, et al. Blood pressure in acute ischemic stroke: challenges in trial interpretation and clinical management position of the ESH Working Group on Hypertension and the Brain. J Hypertens 2018; 12121221.

Trop J Pharm Res, February 2021; 20(2): 291 
11. Yongjun W. Towards precision medicine in ischemic stroke and transient ischemic attack. Front Bio 2018; 23(7): 1338-1359.

12. Yang $S$, Dong-Ping $X$, Zhen $Q$, Peng-Yuan W, Bo-Han $H$, Jian-Guang $Y$, Yong Z, Ben C, Yong-Ling $C$, Min L, et al. Protective cerebrovascular effects of hydroxysafflor yellow A (HSYA) on ischemic stroke. Eur J Pharmcol 2018; 818: 604-609.

13. Lili L, Da S, Jing C, Ming M, Xiaoying Z, Min Z, Jian L. Cocaine and amphetamine regulated transcript (CART) is associated with dopamine and is protective against ischemic stroke. Mol Med Rep 2018; 18-19.
14. Eric U, Laura $C$, Alisha $H$, Debra $H$, Charlotte $S$, Shelton E. Tumor-secreted Pros1 inhibits macrophage M1 polarization to reduce antitumor immune response. $J$ Clin Invest 2018; 128(6): 2356-2358.

15. Reynaert NL, vanderVliet $A$, Guala AS, McGovern T, Hristova M, Pantano C, Heintz NH, Heim J, Ho YS, Matthews DE, et al. Dynamic redox control of NFkappaB through glutaredoxin-regulated Sglutathionylation of inhibitory kappaB kinase beta. Proc Natl Acad Sci USA 2018; 2006 (35): 13086-13091. 